\title{
POLÍTICAS PÚBLICAS NO SEMIÁRIDO ALAGOANO E A RESISTÊNCIA QUILOMBOLA E CAMPONESA FRENTE À EXPLORAÇÃO CAPITALISTA
}

\author{
Mailiz Garibotti Lusa \\ Universidade Federal de Alagoas (UFAL)
}

POLÍTICAS PÚBLICAS NO SEMIÁRIDO ALAGOANO E A RESISTÊNCIA QUILOMBOLA E CAMPONESA FRENTE À EXPLORAÇÃO CAPITALISTA

Resumo: $\mathrm{O}$ artigo discute as políticas públicas, com base na concepção do Estado e suas funções no capitalismo em crise. Faz uma análise do semiárido alagoano, e objetivando mostrar as intencionalidades capitalistas de dominação expressas e subentendidas nos objetivos das políticas públicas. Nesse contexto, aponta as formas de resistência política e cultural das populações quilombolas e camponesas aos mandos do Estado, que ganham significado de lutas sociais e contribuem para a superação da ordem do capital.

Palavras-chave: Semiárido, políticas públicas, quilombolas, resistência.

PUBLIC POLICIES IN THE SEMIARID REGION OF ALAGOAS AND THE RESISTANCE OF POPULATIONS QUILOMBOLAS AND PEASANTS FACE OF CAPITALIST EXPLORATION

Abstract: In this exposition are discussed public policies, based on the conception of the state and its functions in capitalism in crisis. The analysis is specifically directed for the semiarid region of Alagoas and aims point out the intentions of domination capitalist expressed and implied in the public policies objectives. In this circumstances, it presents the forms of political and cultural resistance of populations quilombolas and peasants to the mands to the state, who earn meaning of social struggles and contribute to the overcoming of the capitalist order.

Keywords: Semiarid, public policy, quilombolas, resistance. 
Recebido em 05.01.2014 Aprovado em 06.01.2014

1 INTRODUÇÃO: o marco na pauta do debate - a crise do capital

A crise do capital está estampada mundialmente nas manchetes dos jornais e na face sofrida dos milhões de trabalhadores, inclusive da população do semiárido alagoano. Todas refletem as esferas da crise: econômica, política, social, cultural, de sustentabilidade do planeta e, por que não, do próprio homem. Trata-se de uma crise em sua totalidade, ou como identificou Mészáros (2011), de uma crise estrutural, gerada pelo sociometabolismo do capital, que será superada apenas pela transformação societária.

Inicia-se situando a conjuntura de crise, por entender que para tratar do tema proposto nesta mesa, 'as políticas públicas no semiárido e as formas de resistência à dominação e exploração capitalistas', é imprescindível tomar tal quadro como referência.

Para explicar o quadro de crise e seu agravamento, Mészáros (2011, p. 29) diz que

\begin{abstract}
As recentes tentativas de conter os sintomas da crise [...] só cumprem o papel de sublinhar as determinações causais antagônicas profundamente enraizadas da destrutividade do sistema capitalista. Pois o que está fundamentalmente em causa hoje não é apenas uma crise financeira maciça, mas o potencial de autodestruição da humanidade no atual momento do desenvolvimento histórico [...].
\end{abstract}

Para Chesnais (1998), a crise mundial instalada nos anos 1970 foi solidificando-se, sendo incrementada pela potencialização da especulação financeira como estratégia de aumento fetichizado do capital, pela internacionalização da produção e do capital, pela queda na taxa de lucros e pelo aumento da concorrência internacional, requisitando a reestruturação produtiva na tentativa de recompor a dinâmica de acumulação do capital, que evidencia falhas, mesmo com o aumento exponencial do consumo globalizado.

O semiárido alagoano não está fora deste contexto e, neste sentido, sofre também os rebatimentos desta crise, os quais se agravam pelo descaso político, pelo tradicional mandonismo, pela teimosa concentração de renda, pelas constantes intempéries resultantes da desmedida destruição ambiental. No semiárido despido de políticas públicas efetivas, os efeitos da crise desafiam os trabalhadores à produção e reprodução da vida.

Para organizar esta exposição, foram realizados estudos e análises fundamentados na perspectiva crítica-dialética, abordando qualitativamente a configuração da crise e seus rebatimentos no semiárido alagoano, especialmente a configuração das políticas públicas direcionadas para as populações rurais tradicionais: os quilombolas.

A exposição sintetiza parte das observações dos três anos de exercício docente no semiárido alagoano, junto ao curso de serviço social da Universidade Federal de Alagoas, Campus Arapiraca e está organizada em três partes. Na primeira, trata-se sobre a relação entre capital e Estado, que articulando interesses políticos e econômicos utilizam as políticas públicas como instrumentos de contenção dos conflitos e das lutas da classe trabalhadora, bem como para amenizar as expressões da questão social. Na segunda, discutese sobre os elementos marcantes na configuração do semiárido. E na terceira, sobre as formas de resistência das populações quilombolas ao modelo neodesenvolvimentista atual, expressa pelos questionamentos ao desenho da política a eles direcionada.

\section{DESENVOLVIMENTO}

2.1 Capital e Estado: o papel das políticas públicas nesta aliança

O Estado, para Silva (1999, p. 57), “[...] emerge das lutas sociais e políticas, como lócus institucional da gestão e regulação da vida em sociedade.", cabendo-lhe "administrar tanto o interesse do soberano (res principis), quanto aquele público (res pública)". Na modernidade

[...] o Estado é a ordem jurídica e política que regula um sistema de dominação: do homem pelo homem, segundo Weber; de uma classe social por outra, segundo Marx e Engels. (SILVA, 199, p. 57).

A concepção de Estado e das suas funções vão se transformando. No capitalismo, o soberano passa a ser o capital e o Estado torna-se palco para os gerenciamentos da burguesia, que privilegia seus interesses de classe. Estado e capitalistas aliam-se na defesa do poder político e do poder econômico diante do acirramento da questão social.

Com o agravamento da questão social no século XIX e o avanço dos movimentos populares de perspectiva socialista, intensifica-se o questionamento sobre o papel do Estado. Por outro, a visão liberal do Estado identificado com a nação, garantia de liberdade dos indivíduos, agente do bem-estar coletivo e da justiça social. Por outro lado, a crítica marxista ao Estado como instrumento de opressão de uma classe por outra sob a aparência do equilíbrio e da justiça, ao fazer passar por interesse geral os interesses da burguesia. 
(SILVA, 1999, p. 58).

Ora, é a partir da crítica marxista que se reconhece o papel do Estado na sociedade capitalista. Como dito, ele alia-se à burguesia na defesa dos interesses de ambos, e na invisibilidade daqueles da classe trabalhadora. O que não indica que as lutas dos trabalhadores não pressionaram o Estado na resolução de seus interesses. Pelo contrário, será nos momentos de acirramento das disputas de classe que o Estado se fará presente para gerenciar a crise, utilizando como estratégia o reconhecimento ou a retirada dos direitos - dos trabalhadores - e sua concretização em políticas públicas.

Pereira (2009) confirma isto, ao indicar que o aprofundamento do capitalismo trouxe consigo o desenvolvimento de crises, que se ampliaram a partir de fins do século XIX, gerando conflitos e o agravamento das tensões entre trabalhadores e capitalistas. Neste contexto, o coletivo de trabalhadores, extremamente alijados de autonomia e liberdade, aprimorou sua organização e pressionou o Estado e a sociedade para a conquista de direitos. Naquele tempo também surgiram os sindicatos, e a participação política da classe trabalhadora tornou-se crescente, colaborando para a ampliação das funções do Estado.

Esta foi a conjuntura recente do surgimento das políticas sociais, que para além de se configurarem como mediações para a efetivação de direitos, foram estratégias para a contenção dos conflitos. Assumindo características diferentes em cada tempo histórico e conjuntura econômica, política e social, as políticas públicas caracterizaram diferentes tipos de Estado, sempre cumprindo a função de regulação social, política e econômica.

Com a crise estrutural capitalista - gerada desde os anos 1970 e tornada visível em 2008 -, evidencia-se o esgotamento do sistema. O capital, ameaçado em seu metabolismo de reprodução, volta a assediar o Estado, atribuindo-lhe o gerenciamento da crise, sem abrir mão da sua liberdade produtiva e de mercado. A estratégia é recompor alguns receituários, mesclando parte do (neo)liberalismo com boa dose de (neo) desenvolvimentismo.

O Brasil, mesmo tentando sustentar os índices econômicos, entra em crise. Os sinais visíveis estão nas medidas do Estado - em nada questionadas pelo capital - para a aceleração da economia. A nova estratégia de desenvolvimento, diversa daquela dos 1950 e 1960, opera a "[...] maior abertura do comércio internacional; maior investimento privado na infraestrutura e maior preocupação com a estabilidade macroeconômica. (CASTELO, 2012, p. 624). O desenvolvimentismo se recoloca numa nova roupagem, dizendo-se sustentável.

O novo ideário, apesar de reclamar contraste com o neoliberalismo, associa-se a ele nas suas mais nefastas intencionalidades: a residualidade de alguns tipos de atendimento, especialmente sociais, combinada - e, ao mesmo tempo, contrastada - com medidas de aceleração do consumo e com pesados investimentos na subvenção pública da produção.

Num Estado democrático, supostamente governado por um partido político dos trabalhadores, a aliança entre Estado e burguesia evidencia-se na ampliação dos investimentos sociais, focalizados na transferência de renda para o segmento dos trabalhadores que vivem na miséria, com intenção de torná-los consumidores, enquanto as demais políticas de seguridade são erodidas, assistencializando-se $\mathrm{o}$ atendimento.

Esse é o retrato do Estado e da sociedade em tempo de mundialização do capital, que vive crise estrutural. Nele acirra-se a pobreza e a exclusão, pois se continua gerando o aumento exponencial das desigualdades, através da exploração de classe.

2.2 O Semiárido Alagoano: elementos centrais da sua configuração e a presença camponesa

Em dados breves, neste item serão resgatados os elementos centrais ${ }^{1}$ que conformam o semiárido alagoano, a partir de uma análise da sua formação sócio-histórica. Também se discute a atual presença camponesa, que por si mesma aponta a resistência política, econômica, social e cultural de quem, diante das inúmeras tentativas de subordinação pelo capital, mantém-se permanentemente na luta por autonomia.

A partir da última, percebe-se a concentração de terra e de poder, gerando o coronelismo econômico e social e o mandonismo político, assim como as desigualdades exponenciais. A escravidão negra; a catequização, apresamento, escravidão ou servidão e dizimação das populações indígenas concederam traços às relações sociais e contribuíram para que o cenário das lutas de resistência surgisse no passado e perdurasse no presente, sendo acompanhado pela violência social e política, que marca o presente.

Com o aprofundamento das desigualdades, assim como em outras regiões do país, desde o início do século $X X$ aconteceram levantes de pequenos e médios produtores, que resistiam ao violento processo de expansão das grandes extensões monoculturais e à exploração do trabalhador rural, o que marca a cena política até o momento presente.

Já no século $X X I$, a tendência histórica de concentração de terras e poder permanece, juntamente com outros traços, perpetuando a dominação política das famílias tradicionais, expressa a cada pleito eleitoral, ao lado das lutas sociais dos trabalhadores. Ocorre a ampliação da monocultura, que limita a produção diversificada de alimentos em Alagoas e expulsa os trabalhadores para as cidades da zona da mata e capital.

Embora a predominância seja da produção açucareira em Alagoas, no semiárido encontra-se a produção de leite, o cultivo de frutas e de algumas oleaginosas como o amendoim. Aí são produzidas as culturas que oferecem sustentação para a produção leiteira - a bacia leiteira se concentra no sertão - e 
de gado, como por exemplo, o cultivo da palma.

O tipo de propriedade rural que predomina é de pequenos e médios produtores, embora haja a presença de grandes produtores. Nessa região há menor incidência do latifúndio, o que não indica, contudo, que ele não se faça presente. Consequentemente, no semiárido existe uma maior diversificação da produção agrícola, comparativamente ao litoral e à zona da mata, onde predomina a monocultura da cana. Assim, é no semiárido alagoano que a unidade camponesa de produção familiar é mais presente. Essa população camponesa que trabalha com a produção familiar é potencialmente usuária de programas e serviços instituídos nas políticas sociais do governo federal. Este dado aponta que a maioria da população tem baixa renda familiar, não conseguindo extrair do campo os recursos necessários para a subsistência, o que colabora para o fluxo migratório (LUSA, 2013).

Outro aspecto é que, embora dizimados, os povos indígenas ainda ocupam pequenos territórios em Alagoas. O agreste é a região semiárida que mais possui aldeias indígenas reconhecidas pela FUNAI, sendo o município de Palmeira dos Índios o território com maior número de aldeias: seis no total (LUSA, 2011). Em menor número, mesmo assim presentes, estão os territórios quilombolas reconhecidos pelo Estado, outros em fase de reconhecimento e outros ainda reivindicando por eles. A constatação da presença das populações tradicionais, em especial no semiárido, indica a permanente luta dessas comunidades pela posse e uso da terra, segundo os seus princípios e valores culturais, de vida e de trabalho. Nestes territórios tradicionais a ocupação das terras é geralmente comunal e a produção voltase para a subsistência familiar e comunitária, bem como para a pequena comercialização nas feiras semanais promovidas nas cidades (LUSA, 2013).

Outro elemento que vem marcando o semiárido alagoano nas últimas três décadas é o processo de ocupações de terras por camponeses organizados em movimentos sociais, com destaque para o Movimento de Trabalhadores Rurais Sem Terra $(\mathrm{MST})^{2}$. Essa presença tem sido constante em todo o território estadual, inclusive no semiárido, explicitando os conflitos fundiários e a exclusão do acesso a terra (LUSA, 2012).

Oclimasemiáridoeosseguidosprolongamentos da estação seca deixam o território em permanente alerta e exigem das mulheres e dos homens do campo muita persistência e criatividade na produção da vida cotidiana. Eles não arrefecem forças nesta luta diária e, como resultado, o semiárido é o lugar de maior diversidade de produtos agrícolas do Estado: fruticultura, bovinocultura e ovinocultura de leite e de corte, avicultura de corte e postura, produção de grãos como o milho e de leguminosas como o feijão e a fava, somam-se a produção de macaxeira, inhame, abóboras, temperos e a horticultura (LUSA, 2013).

A partir desse panorama é possível perceber a diversidade de organização econômica, política, social e cultural que constitui o semiárido rural alagoano. Como efeito, evidencia-se a produção de vasto tecido de desigualdades sociais, pobreza e miséria. Este semiárido configura-se como produtor de demandas para os serviços de atendimento às políticas públicas, os quais mediam a efetividade dos direitos sociais, especialmente.

\subsection{Quilombolas: políticas públicas e resistência cultural}

A história das populações quilombolas no Brasil é herança dos séculos de ocupação e dominação portuguesa, fundada na exploração da força de trabalho dos negros africanos escravizados pelo branco europeu. Essa história remonta o contínuo processo de lutas e resistências expressas nas fugas, revoltas e surgimento dos quilombos (DIEGUES JÚNIOR, 2002). Elas se reconfiguram atualmente quando os quilombolas exigem reconhecimento do Estado como povos tradicionais, o direito a terra e a preservação da cultura e história.

Em Alagoas existem 52 territórios quilombolas, segundo dados da 'Rede Mocambo's (2008). A Comunidade Quilombola da Tabacaria, de Palmeira dos Índios, foi a primeira legalizada como 'território remanescente de quilombos', em 2008, recebendo a titulação das terras em 2011. Embora tais conquistas sejam importantes, pela garantia legal que representam, entende-se que no aspecto objetivo da reprodução material da vida ocorreram escassos avanços e as famílias continuam residindo em casas cobertas por lonas, sem atendimento de água e esgotos, sem acesso local aos atendimentos básicos de saúde e educação fundamental e média, com transporte público precário e insuficiente, sem orientações técnicas para produção agrícola, sem investimentos no âmbito cultural para a preservação dos costumes e valores quilombolas (COSTA, 2013).

Segundo a Constituição Federal de 1988 (BRASIL, 1988), em seu Art. 215, o Estado deverá garantir a todos o pleno exercício dos direitos culturais. Já no Art. 216, que versa sobre o patrimônio cultural brasileiro, o inciso $5^{\circ}$ determina que "ficam tombados todos os documentos e sítios detentores de reminiscências históricas dos antigos quilombos". Assumindo o Estado a manutenção do patrimônio histórico tombado, significa que o reconhecimento oficial da 'memória quilombola' implica em assegurar às comunidades as condições necessárias para preservar e cultivar tal tipo de reminiscência.

Além desses preceitos Constitucionais, há uma série de Leis posteriores a 1988, que oferecem fundamentação legal para o desenho das políticas quilombolas, cujas expressões atuais são o Programa Brasil Quilombola e a Agenda Social Quilombola. Neles são previstos o acesso a terra, à infraestrutura e qualidade de vida, incluindo a promoção à saúde, à educação quilombola, o acesso à energia elétrica, 
à transferência de renda etc.

Mesmo contando com leis e políticas públicas específicas, o que se percebe na Comunidade da Tabacaria é a ausência quase total do Estado, invisibilizada pelas mídias locais e estadual. Essa situação é razão suficiente para atestar a ausência do Estado. Quando não são executados tais serviços básicos na comunidade, obriga-se os quilombolas a deslocamentos diários e/ou emergenciais, todavia, considerando que o serviço de transporte - também considerado direito social - é precário e insuficiente, o resultado desta operação é a negação objetiva de diversos direitos fundamentais (COSTA, 2013).

Por causa destas adversidades e negações sobrepostas de direitos, o cotidiano da comunidade é embebido em lutas sociais, ora explícitas, ora não, e a resistência às políticas populistas e eleitoreiras é uma das suas expressões. Para isto, a comunidade mantém-se organizada como forma de resolver as demandas cotidianas emergentes, lutar pelos direitos que lhes são negados e cultivar os costumes e tradições. Expressão concreta está na Associação de Desenvolvimento da Comunidade Remanescente de Quilombo Tabacaria, criada em 2005, para organizar e mobilizar a luta social e política pelo acesso a terra e às condições materiais de vida, tomando como base organizativa sua identidade étnica e rural.

\section{CONCLUSÃO}

O latifúndio, a monocultura, a escravidão, a violência, as relações de compadrio, as desigualdades sociais crescentes se tornaram marcas indeléveis na conformação atual da sociedade e Estado alagoanos. O semiárido acompanhou este processo, recebendo ainda outras marcas próprias do clima e da geografia. Tais determinantes não podem ser invisibilizados quando se trata de mobilizar os quadros de resistência à exploração capitalista, principalmente, quando se trata da organização da classe trabalhadora para a transformação societária, aproveitando os tempos de crise estrutural (LUSA, 2013).

As conquistas parciais de direitos da Comunidade Quilombola da Tabacaria representam o fundamento para as lutas ainda necessárias, diante da negação de tantos outros direitos. A ausência do Estado é evidente e motiva as representações da comunidade a denunciarem o abandono, mobilizando-a internamente para se organizar e exigir serviços que assegurem efetivamente seus direitos. Ora, eis no semiárido alagoano uma expressão das lutas atuais da classe trabalhadora em resistência à lógica do capital, denunciando as contradições do sistema e os antagonismos de classes que lhes são próprios.

Ora, já dizia Mészáros (2011, p. 48), "[...] a questão não é 'se haverá ruptura ou não', mas por quais meios vão ocorrer". Então, neste momento urge reforçar as lutas sociais, para que possam significar efetivamente a contra-hegemonia ao capitalismo, ao produzirem consciência crítica e política da classe trabalhadora, emancipando-a politicamente, mobilizando-a e incentivando-a à luta para, quiçá, chegar à transformação societária.

\section{REFERÊNCIAS}

BRASIL. Presidência da República. Constituição da República Federativa do Brasil. Brasília, DF, 1988. Disponível em: <http://www.planalto.gov.br/ ccivil_03/Constituicao?Constituicao.htm>. Acesso em: 4 dez. 2011.

Secretaria Especial para Políticas de Promoção de Igualdade Racial. Programa Brasil Quilombola. Brasília, DF: MDA/SEPPIR, 2011.

CASTELO, Rodrigo. O novo desenvolvimentismo e a decadência ideológica do pensamento econômico brasileiro. Serviço Social e Sociedade, São Paulo, ano XXXII, n. 112, p. 613-636, out./dez. 2012.

CHESNAIS, François. Rumo a uma mudança total dos parâmetros econômicos mundiais dos enfrentamentos políticos e sociais. Outubro, São Paulo, n. 1, p. 7-31, 1998. Disponível em: < http:// revistaoutubro.com.br/edicoes/01/out01_01.pdf >. Acesso em: 23 abr. 2012.

COSTA, Érika et al. Práticas pedagógicas do Serviço Social brasileiro: uma experiência de educação do campo. In: CONGRESO ARGENTINO Y LATINOAMERICANO DE ANTROPOLOGÍA RURAL, 5., 2013, Santa Rosa, La Pampa. Anais... Santa Rosa, La Pampa, Argentina: Núcleo Argentino de Antropología Rural, 2013.

LUSA, Mailiz Garibotti. Questão rural e Serviço Social: a trajetória de uma relação e o exercício profissional na atualidade. 2011. 140 f. Projeto de doutoramento (Doutorado em Serviço Social)Programa de Estudos Pós-Graduados em Serviço Social, Pontifícia Universidade Católica de São Paulo, São Paulo, 2011.

\section{A (in)visibilidade do Brasil rural no Serviço} Social: o reconhecimento dos determinantes a partir da análise da mediação entre a formação e o exercício profissional em Alagoas. 2012. 394 f. Tese (Doutorado em Serviço Social) - Programa de Estudos Pós-Graduados em Serviço Social, Pontifícia Universidade Católica de São Paulo, São Paulo, 2012.

O rural no semiárido e a formação sócio histórica de Alagoas. In: ALMEIDA, Luiz Sávio de; LIMA, José Carlos da Silva; OLIVEIRA, Josival dos Santos. Terra em Alagoas. Maceió: UFAL, 2013. 
Mimeo. Livro em fase de editoração

MÉSZÁROS, István. A crise estrutural do capital. Trad.: Francisco Raul Cornejo et al. 2. ed. rev. e ampliada. São Paulo: Boitempo, 2011.

REDE MOCAMBO. 20Tabacaria é o primeiro território reconhecido como quilombola pela União em Alagoas. [S. I.: s. n.], 2008. Disponível em: <http://www.mocambos.org/noticias/tabacaria>. Acesso em: 21 jul.2012.

SILVA, Ademir Alves. As relações estado-sociedade e as formas de regulação social. In: CONSELHO FEDERAL DE SERVIÇO SOCIAL; ASSOCIAÇÃO BRASILEIRA DE ENSINO E PESQUISA EM SERVIÇO SOCIAL; UNIVERSIDADE DE BRASÍLIA. Capacitação em Serviço Social e Política Social - Módulo 2: Reprodução social, trabalho e serviço social. Brasília, DF: CEAD, 1999. p. 55-71.

PEREIRA, Potyara Amazoneida Pereira. Estado, sociedade e esfera pública. In: CONSELHO FEDERAL DE SERVIÇO SOCIAL; ASSOCIAÇÃO BRASILEIRA DE ENSINO E PESQUISA EM SERVIÇO SOCIAL. Serviço Social: direitos sociais e competências profissionais. Brasília, DF, 2009. p. 285-300.

\section{NOTAS}

1 Uma análise mais detalhada da formação sóciohistórica do Semiárido Alagoano, da qual retiramse os elementos centrais que o caracterizam na atualidade, pode ser encontrada não parte I da tese "A (in)visibilidade do Brasil rural no Serviço Social: o reconhecimento dos determinantes a partir da análise da mediação entre a formação e o exercício profissional em Alagoas", defendida na PUC-SP em 2012, e no artigo "O rural no Semiárido e a formação sócio-histórica de Alagoas", publicado no livro "Terra em Alagoas" (2013), pela EDUFAL

2 Em relação a este aspecto das lutas sociais no campo na atualidade, há de se registrar no semiárido alagoano a presença de uma associação de camponeses, surgida no ano de 2006 e que desde abril de 2011 passou a se identificar como movimento social: o Movimento de Trabalhadoras e Trabalhadores do Campo de Alagoas (MTC-AL). Antes reconhecido como Associação dos Moradores do Agreste Alagoano (AMIGREAL), o MTC-AL volta suas ações tanto para a educação do campo, quanto para a luta pela conquista da terra, utilizando a mesma estratégia adotada por outros movimentos sociais camponeses, qual seja a ocupação de terras consideradas, pelo movimento, como devolutas e improdutivas.

3 Para melhor aprofundamento sugere-se ler o artigo completo da Rede Mocambo (2008), disponível em: http://www. mocambos.org/noticias/tabacaria-e-o-primeiro-territorioreconhecido-como-quilombola-pela-uniao-em-alagoas

\section{Mailiz Garibotti Lusa}

Assistente Social

Doutora em Serviço Social pela Pontifícia Universidade Católica de São Paulo (PUC/SP)

Professora do Curso de Serviço Social da Universidade Federal de Alagoas (UFAL) - Campus Arapiraca E-mail: mailizlus@yahoo.com.br

\section{Universidade Federal de Alagoas - UFAL}

Campus Arapiraca - Unidade Educacional de Palmeira dos Índios - Rua Sonho Verde, s/n, Eucalipto.

57606-100 - Palmeira dos Índios - AL. 